\title{
Evaluating bending stiffness and resistance of sandwich panels at elevated temperatures
}

\author{
Ashkan Shoushtarian Mofrad ${ }^{1}$, Darita Shlychkova ${ }^{2}$, Yvonne Ciupack ${ }^{3}$, Hartmut Pasternak ${ }^{4}$ \\ Chair of Steel and Timber Structures, Brandenburg University of Technology, Cottbus, Germany

\section{E-mail: ${ }^{1}$ ashkan.shoushtarianmofrad@b-tu.de (corresponding author)}

\begin{abstract}
The objective of this research is to develop a modeling and simulation approach for the bending stiffness of sandwich panels which have been verified and compared by experimental results in normal condition and fire case. For this purpose, polyisocyanurate (PIR) foam has been used as core material along with trapezoidal sheeting. In order to simulate the experiments, Finite Element (FE) software ABAQUS has been applied. The modelling process contains heat transfer analyses, mechanical analyses in normal condition and sequential analyses which includes the combination of both mechanical analyses and thermal analyses. The main aim of this paper is to investigate the effect of fire on the bending stiffness and stabilization of sandwich panels. Although with increase in temperature the strength of panels decreases, this decline is not linear. The presented work should be considered as first step in STABFI project financed by Research Fund for Coal and Steel (RFCS) which its purpose is to investigate translational and also torsional stiffness of sandwich panels as future work. STABFI stands for steel cladding systems for stabilization of steel buildings in fire.
\end{abstract}

Keywords: Sandwich panels, PIR-core, fire resistance, finite element modelling, bending stiffness.

\section{Introduction}

Sandwich panels are a construction system, commonly used to clad the outside of buildings or to divide internal spaces where thermal insulation is necessary. They are popular because they are an efficient, lightweight system and easy to be produced and installed. Although PIR cores have high thermal conductivity and low density, one of the main problems is smoke that is produced by panel at temperatures higher than $300^{\circ} \mathrm{C}$. This issue can create huge problems for firefighters and residents of buildings (Stec \& Hull, 2011). Also, the resistance of sandwich panels with trapezoidal sheeting in fire depends on the catenary action. The catenary action is a load carrying mechanism where the bending moment capacity of the beam (panel) is negligible but the beam (panel) will still be able to resist the applied transversal load with the tension force developed in the beam (panel) via further deflection even with reduced material strength (Lu, Mäkeläinen, \& Outinen, 2007). In this research, as a part of STABFI project, the focus is on on the bending performance of sandwich panels during fire. Usually sandwich panels are used as horizontal and vertical panels for ceilings and walls in single story buildings. All bending experiments and tests of material properties were carried out in laboratory of Faculty of Civil Engineering, Czech Technical University in Prague.

\section{Test arrangement}

For testing sandwich panels with thicknesses of $100 \mathrm{~mm}$ and $160 \mathrm{~mm}$ were chosen. The loading-heating order is the following: at first the displacement is monotonically increased up to around $2.5 \mathrm{~mm}$ and then the temperature is increased by means of ceramic heating pads until definded temperatures which are 200,250 and $300{ }^{\circ} \mathrm{C}$ in this research. After that the displacement again is risen until a failure occurs. Due to enormous amount of smoke generated by PIR during heating, specimens were heated maximum up to $300^{\circ} \mathrm{C}$. The test setup is shown in Figure 1 . The vertical load is transferred to the panel through 4 beams HEA120 (steel grade S355) $1000 \mathrm{~mm}$ length. The load has been generated by the hydraulic jack. Rate of loading is set to constant value of $0.05 \mathrm{~mm}$ per second. As can be seen in Figure 1 the load is applied from upper side of the panel. The panel has inner sheet thickness of $0.4 \mathrm{~mm}$ and outer sheet thickness of $0.5 \mathrm{~mm}$, also its width is $1000 \mathrm{~mm}$. The detailed information is shown in Figure 2. 


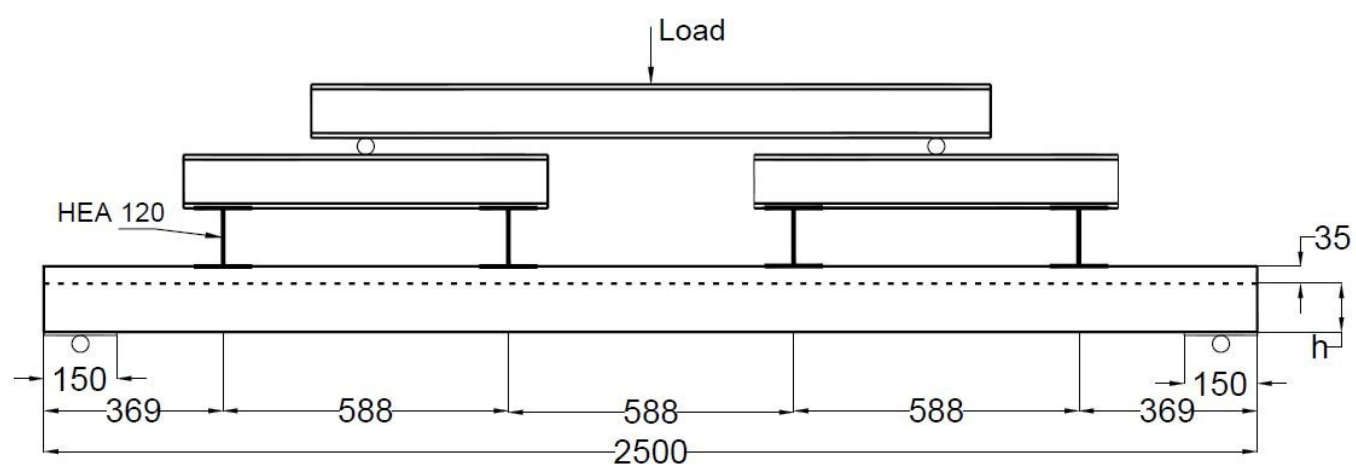

Figure 1. Test arrangement of PIR core $100 \mathrm{~mm}$, dimensions in $\mathrm{mm}$

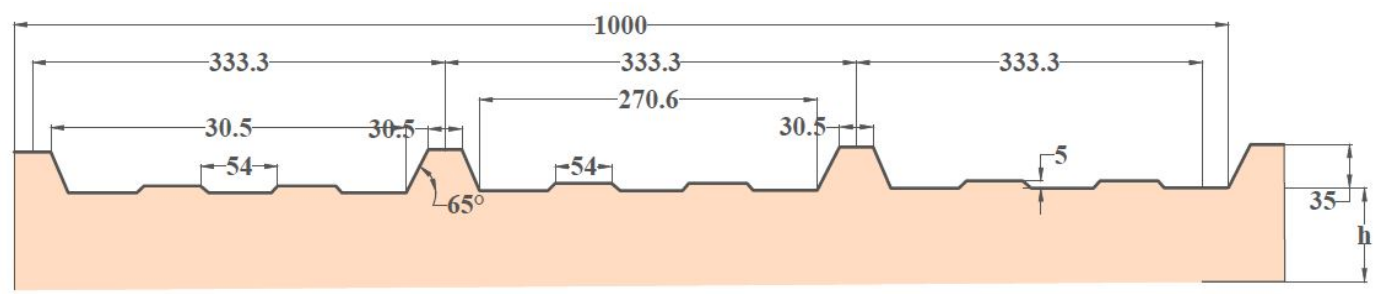

Figure 2. Cross-section of panel PIR core $100 \mathrm{~mm}$, dimensions in $\mathrm{mm}$

The specimens were tested at room temperature $\left(20^{\circ} \mathrm{C}\right)$ and also at elevated temperatures $150,200,250$ and $300{ }^{\circ} \mathrm{C}$. Heating of the steel sheet until these temperatures is conducted by means of ceramic heating pads. The heating pads were uniformly distributed on the inner sheet of the panel. Mechanical loading of the panel started when the temperature of the inner panel sheet reached the expected one.

Horizontally restrained supports were provided by steel sections fixed to the bearing structure from bottom surface. The support was composed of two steel $10 \mathrm{~mm}$ thickness plates placed on the edges of the panel. The panel was fixed to both plates of size $150 \times 1000 \mathrm{~mm}$. Circular rods of diameter $50 \mathrm{~mm}$ were welded to the lower plates in order to prevent any movement of the panel during loading. The supports enabled the panel to act as a catenary.

During the tests, deflections of the panel were recorded by transducers in 5 locations (see Figure 3). Loading force and temperature of the inner, outer sheet and the panel were also recorded in several locations. In Figure 4, one specimen before and after test has been shown. It can be seen that the maximum defoemation of panels in most cases appears in the vicinity of mid-spans especially when the test arrangements are symmetrically prepared, and the exposed side of panels due to heating deformed outwards. The failure of panels usually occurs close to the supports.

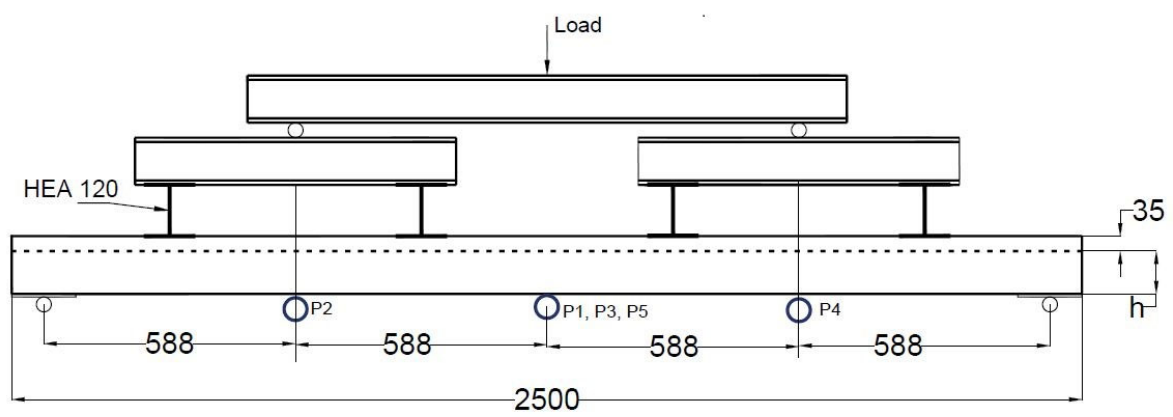

Figure 3. Location of transducers in the lower face of the panel, dimensions in $\mathrm{mm}$

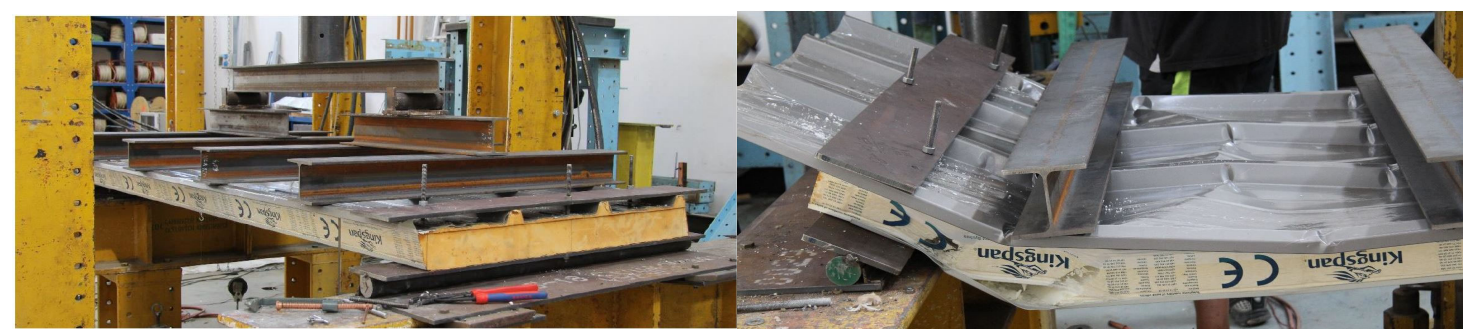

Figure 4. Specimen, left: before test, right: after test (failure of panel core) 


\section{FE modelling}

In this study, 3D finite element model is developed using ABAQUS software (ABAQUS, n.d.) in order to simulate the bending tests of sandwich panel under vertical loading at both ambient and elevated temperatures. The model considers the material nonlinearity, geometric nonlinearity and contact behaviour which is "Tie" between core and steel facings. Threedimensional 8 node solid elements with reduced integration points (C3D8R) are chosen for modelling the PIR core while in order to improve the computational efficiency, the facings are simulated by S4R shell elements. The loading-heating order is like this: first a pre-load around $2 \mathrm{kN}$ is applied and then the panel is heated up to the defined temperature, and finally by keeping it again mechanical loading is applied. In the Table 1 the thermal conditions are presented.

Table 1. Test temperatures for specimens

\begin{tabular}{|c|c|}
\hline \multicolumn{2}{|c|}{ Test matrix } \\
\hline Cladding thickness $(\mathrm{mm})$ & Temperature $\left({ }^{\circ} \mathrm{C}\right)$ \\
\hline \multirow{3}{*}{100} & 20 \\
\cline { 2 - 2 } & 200 \\
\cline { 2 - 2 } & 250 \\
\cline { 2 - 2 } & 300 \\
\hline \multirow{3}{*}{160} & 20 \\
\cline { 2 - 2 } & 150 \\
\cline { 2 - 2 } & 200 \\
\hline
\end{tabular}

Figure 5 shows the dimensions of the studied model while the thickness of core between $100 \mathrm{~mm}$ and $160 \mathrm{~mm}$ varies. The thicknesses of bottom and top sheets are $0.4 \mathrm{~mm}$ and $0.5 \mathrm{~mm}$ respectively.

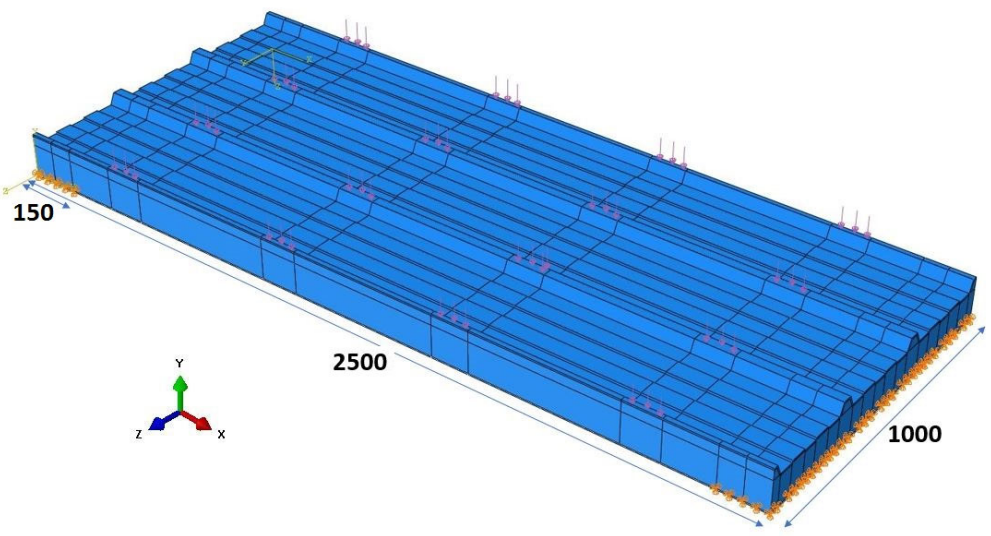

Figure 5. Dimensions of structural model, dimensions in $\mathrm{mm}$

Table 2. Values of thermal conductivity at normal and elevated temperatures for PIR core (Wang \& Foster, 2017)

\begin{tabular}{|c|c|}
\hline Temperature $\left({ }^{\circ} \mathrm{C}\right)$ & Thermal Conductivity $(\mathrm{W} / \mathrm{mK})$ \\
\hline 1 & 0.029 \\
\hline 20 & 0.031 \\
\hline 50 & 0.034 \\
\hline 100 & 0.039 \\
\hline 200 & 0.051 \\
\hline 300 & 0.065 \\
\hline 400 & 0.083 \\
\hline 500 & 0.104 \\
\hline 600 & 0.130 \\
\hline 700 & 0.162 \\
\hline 800 & 0.199 \\
\hline 900 & 0.242 \\
\hline 1000 & 0.293 \\
\hline
\end{tabular}


The boundary conditions are defined so that edge surfaces of $150 \times 1000 \mathrm{~mm}$ of the sandwich panel are fixed in $\mathrm{X}, \mathrm{Y}$ and $\mathrm{Z}$ directions (see Figure 5). Mechanical loading is applied directly to the top sheet at 16 areas and in the certain distances according to Figure 1 and 5. The width of each loading area is $120 \mathrm{~mm}$ which is equal to the flange width of HEA 120.

The material used for the facings is assumed to be steel grade S250GD and thermal properties of steel are defined according to EN 1993-1-2 (Eupoean Committee for Standartization, 2005). All thermal properties for PIR core such as thermal conductivity and specific heat are taken from the literature (Wang \& Foster, 2017); however, the mechanical properties are received from the testing conducted in laboratory of company Kingspan. Although PIR core is an orthotropic material, in this research, after comparing output results and observing negligible differences between isotropic and orthotropic materials, as a simplification, the PIR core is considered as an istropic material (Figure 6).

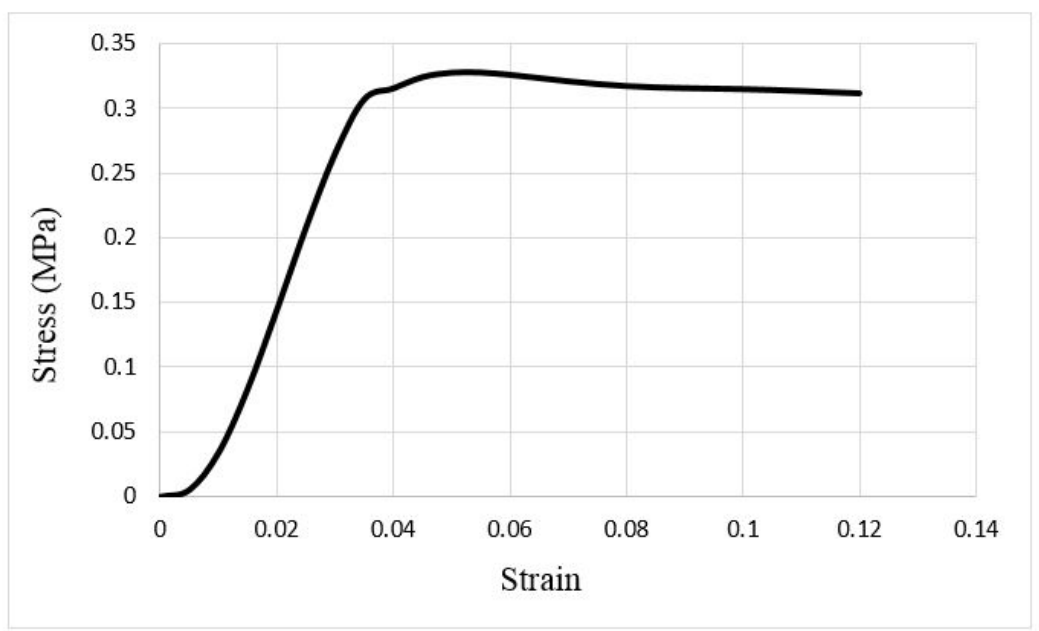

Figure 6. Stress-strain curvature for PIR core

\section{Results and discussion}

\section{Temperature distribution}

As a sample in Figure 7, the temperature distribution of experimental and numerical results of panel with PIR core $100 \mathrm{~mm}$ thickness and exposed temperature $300{ }^{\circ} \mathrm{C}$ has been compared. As can be seen, there is relatively good agreement between them. The average temperature of lower sheet (exposed side) was given to ABAQUS as input data; as a result, the curvature of lower sheet for experiment and simulation are exactly coincident, and average temperature of upper and core has been taken as output.

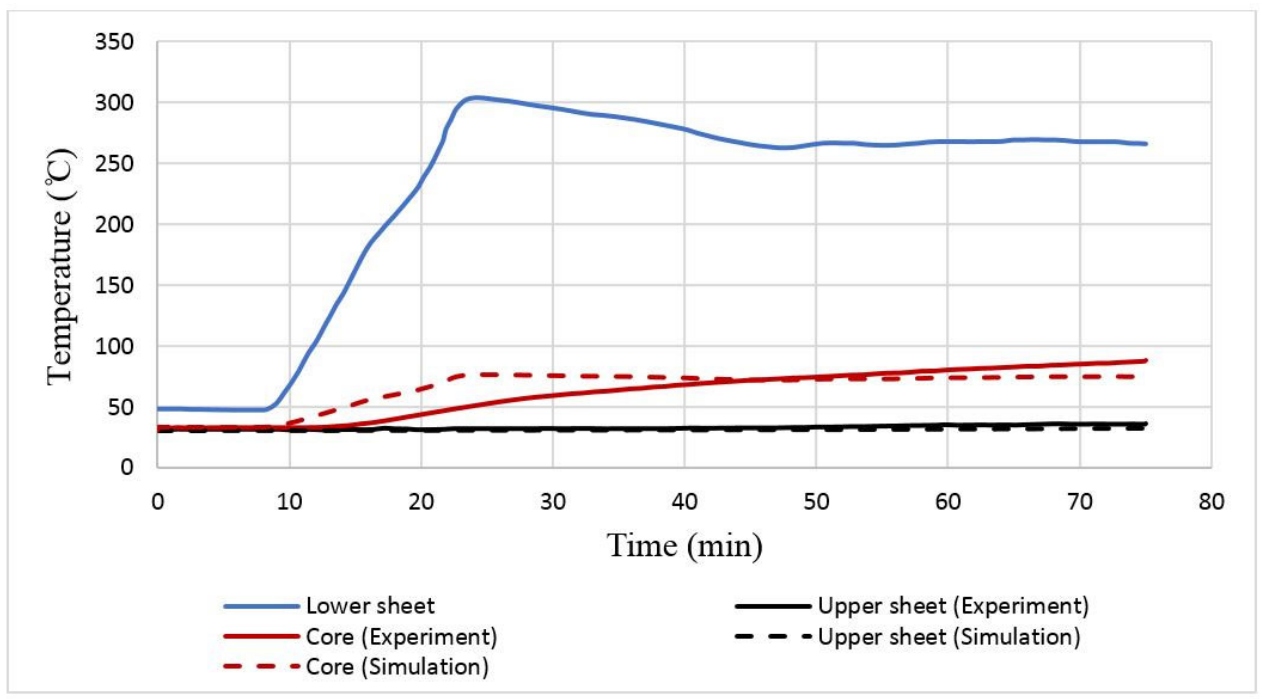

Figure 7. Average temperature distribution from experiment and simulation for PIR core $100 \mathrm{~mm}$ with temperature $300^{\circ} \mathrm{C}$ 


\section{Load-displacement diagrams}

In normal condition the experimental and numerical results for two different thicknesses have been compared. It can be seen in Figure 8, acceptable agreement exists between results. In experimental results, there are some jumping (sharp movement) that is due to sensivity of tranducers during tests. As expected, by increasing the thickness of panel, the load bearing would be greater. For example, when the thickness changes from $100 \mathrm{~mm}$ to $160 \mathrm{~mm}$, the load capacity increases up to $53.5 \%$; furthermore, the bending stiffness of panel rises around $39 \%$.

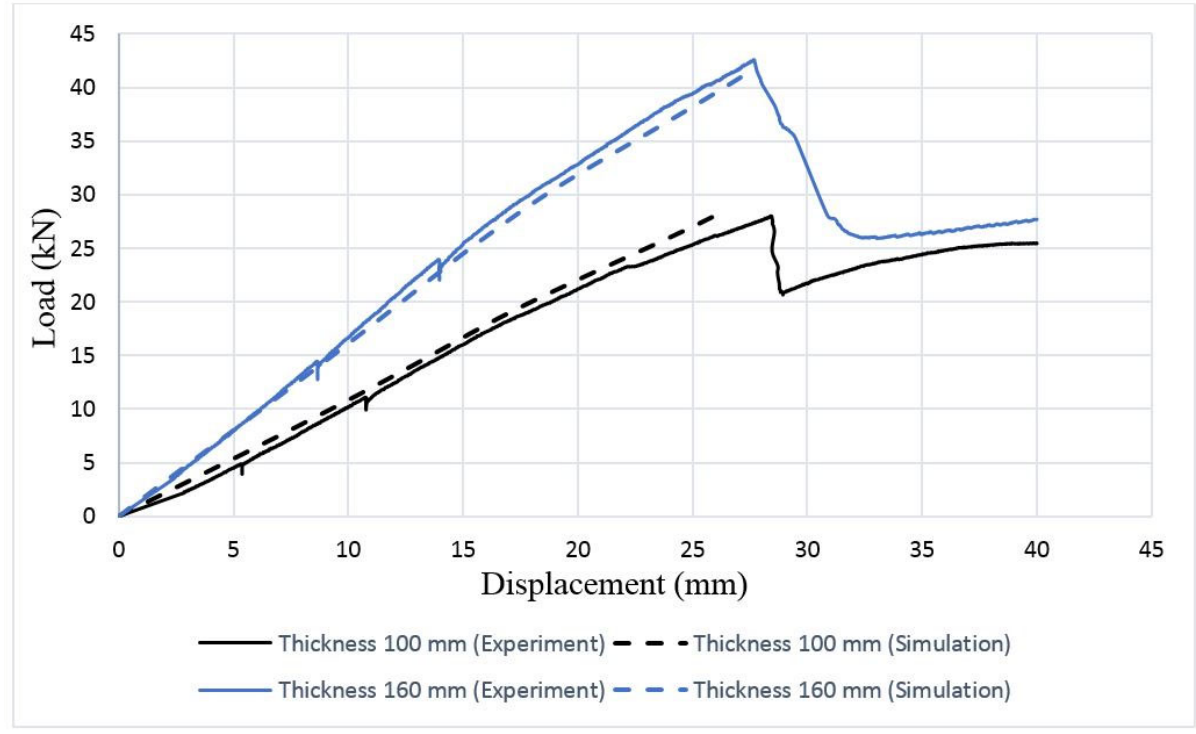

Figure 8. PIR core at room temperature with thicknesses $100 \mathrm{~mm}$ and $160 \mathrm{~mm}$

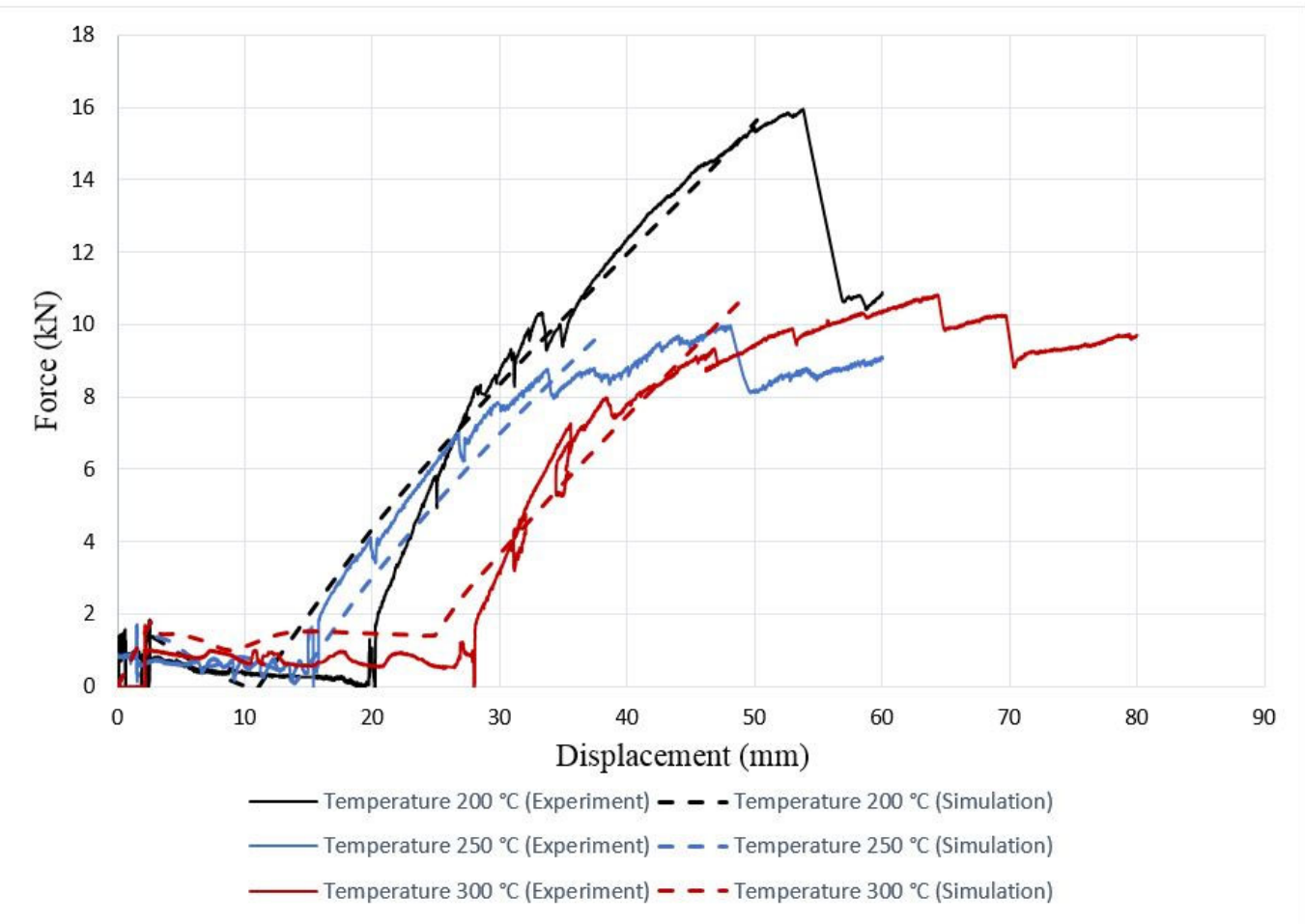

Figure 9. Force-displacement curves for panel $100 \mathrm{~mm}$ at temperatures (a): $200{ }^{\circ} \mathrm{C} ;(\mathrm{b}): 250{ }^{\circ} \mathrm{C} ;(\mathrm{c}): 300{ }^{\circ} \mathrm{C}$

Figure 9 illustrates load-displacement curvatures for sandwich panels with thickness $100 \mathrm{~mm}$ for three different temperatures. The maximum value of strength decreases when temperature rises. Also, by increasing temperature, as expected, the bending stiffness reduces; however, this decrease - as can be seen - is not linear. In the cases studied, the differences between $250{ }^{\circ} \mathrm{C}$ and $300{ }^{\circ} \mathrm{C}$ seem to be not significant while the result differences between $200{ }^{\circ} \mathrm{C}$ and $250{ }^{\circ} \mathrm{C}$ are remarkable. At $300{ }^{\circ} \mathrm{C}$ there is a big difference between force-displacement curves that were recorded by 
P1-P5 transducers (see Figure 3), while at temepratures of $200^{\circ} \mathrm{C}$ and $250{ }^{\circ} \mathrm{C}$, they are more convergent (Figure 10). It can occur due to different reasons, e.g. additional displacement of transducers at rather high temperature as $300{ }^{\circ} \mathrm{C}$. In fact, the transducers at high temperatures are more sensitive, and to keep them in situ is more difficult; therefore, at $300{ }^{\circ} \mathrm{C}$ temperature the differences between curves outputs as well as backward movements are observed.
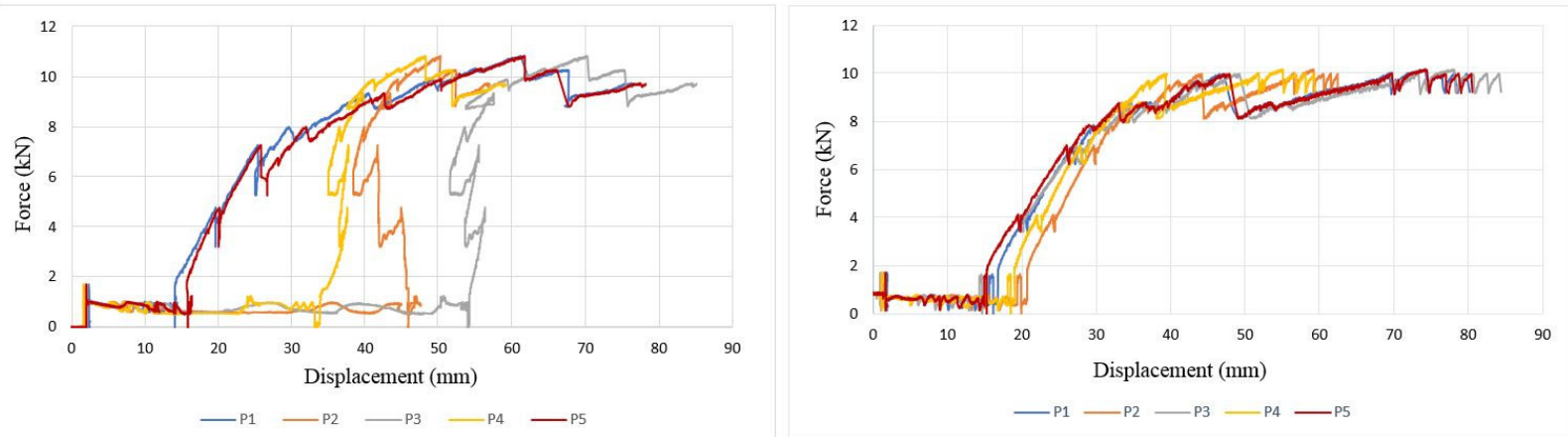

Figure 10. Force-displacement curves for transducers in laboratory at, left: $300{ }^{\circ} \mathrm{C}$, and right: $250{ }^{\circ} \mathrm{C}$

Figure 11 shows two different temperatures for sandwich panel of $160 \mathrm{~mm}$ thickness. As the aim of this research is to investigate bending stiffness of sandwich panels, it can be seen that there is good correlation between curvatures. Actually, the experimental and numerical results are such as two parallel lines that shows the same stiffness. The maximum load capacity for $150{ }^{\circ} \mathrm{C}$ and $200{ }^{\circ} \mathrm{C}$ is around $26 \mathrm{kN}$ and $24 \mathrm{kN}$ respectively which indicates the decrease of maximum force when temperature rises $50{ }^{\circ} \mathrm{C}$. Even though the experimental measured displacements are rather higher than numerical ones, two important parameters for this research are maximum load capacity and stiffness which sound agreeable.

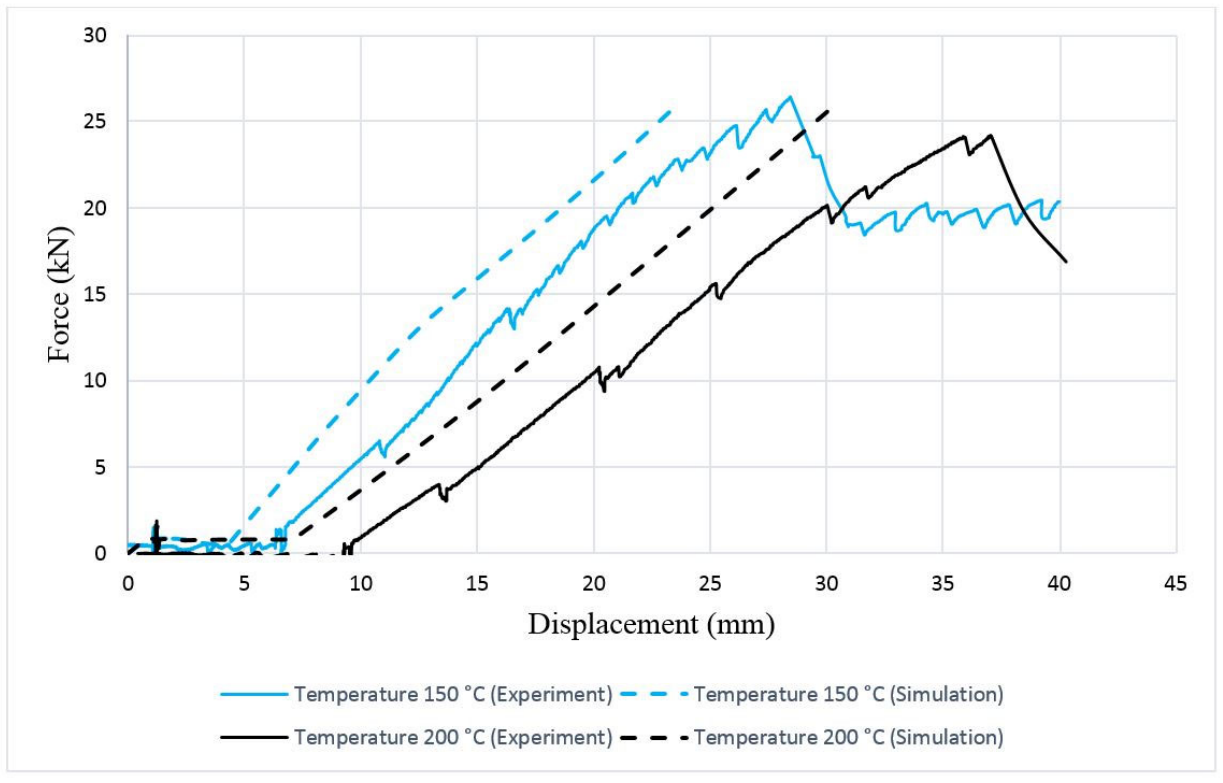

Figure 11. Force-displacement curves for panel $160 \mathrm{~mm}$ at temperatures (a): $150{ }^{\circ} \mathrm{C}$; (b): $200{ }^{\circ} \mathrm{C}$

\section{Conclusions}

3D finite element models including material and geometric non-linearity have been created to verify the bending stiffness of sandwich panels at both room and elevated temperatures. The final aim of research is to use the bending stiffness as input data for spring models. The results reveal that by increasing temperature up to $200{ }^{\circ} \mathrm{C}, 250{ }^{\circ} \mathrm{C}$ and $300{ }^{\circ} \mathrm{C}$ the maximum load decreases until $41.8 \%, 63.6 \%$ and $60 \%$ respectively for $100 \mathrm{~mm}$ thickness. This trend for $160 \mathrm{~mm}$ thickness for $150{ }^{\circ} \mathrm{C}$ and $200{ }^{\circ} \mathrm{C}$ is $38 \%$ and $42.8 \%$. When temperature is $300{ }^{\circ} \mathrm{C}$, more discrepancies between transducers data are observed (see Figure 10). This can be due to the sensitivity of transducers at higher temperatures and difficulties to keep them in situ. The negligible differences between FE model and testing can be derived from material properties specially at elevated temperatures and imperfection because cracks and failure have not been considered in the FE models. Moreover, when simulating sandwich panel under fire, there are many challenging problems including 
delamination of the face sheet, ablation of the core and large geometrical distortions that affect the simulation process. For future work the temperatures higher than $300{ }^{\circ} \mathrm{C}$ and different thicknesses of sandwich panels will be investigated.

\section{Acknowledgement}

This project has received funding from the Research Fund for Coal and Steel under grant agreement No 751583. The authors would like to express great thanks to Prof. F. Wald and his colleagues from Department of Steel and Timber Structures, Czech Technical University in Prague who carried out the bending tests in laboratory of Faculty of Civil Engineering, and also thank Kingspan who provided the authors with material properties of PIR cores as well as other partners of STABFI project who had contribution to this research.

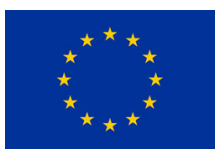

\section{References}

ABAQUS online documentations, version 6.13. (n.d.). Retrieved from http://dsk.ippt.pan.pl/docs/abaqus/v6.13/index.html Eupoean Committee for Standartization. (2005). Eurocode 3. Design of steel structures - Part 1-2: General rules - Structural fire design (EN 1993-1-2). Brussels.

Lu, W., Mäkeläinen, P., \& Outinen, J. (2007). Numerical simulation of catenary action in cold-formed steel sheeting in fire. Journal of Structural Mechanics, 40(3), 28-37.

Stec, A. A., \& Hull, T. R. (2011). Assessment of the fire toxicity of building insulation materials. Energy and Buildings, 43(2-3), 498-506. https://doi.org/10.1016/j.enbuild.2010.10.015

Wang, Y. C., \& Foster, A. (2017). Experimental and numerical study of temperature developments in PIR core sandwich panels with joint. Fire Safety Journal, 90, 1-14. https://doi.org/10.1016/j.firesaf.2017.03.003 